\title{
Article
}

\section{Caesarean section for non-medical reasons at term}

Lavender, Tina, Hofmeyr, G Justus, Neilson, James P, Kingdon, Carol and Gyte, Gillian ML

Available at https://clok.uclan.ac.uk/4111/

Lavender, Tina, Hofmeyr, G Justus, Neilson, James P, Kingdon, Carol orcid iconORCID: 0000-0002-5958-9257 and Gyte, Gillian ML (2012) Caesarean section for non-medical reasons at term. The Cochrane Library, - (-). pp. 1-18. ISSN 1469-493X

It is advisable to refer to the publisher's version if you intend to cite from the work. http://dx.doi.org/10.1002/14651858.CD004660.pub3

For more information about UCLan's research in this area go to http://www.uclan.ac.uk/researchgroups/ and search for < name of research Group>.

For information about Research generally at UCLan please go to http://www.uclan.ac.uk/research/

All outputs in CLoK are protected by Intellectual Property Rights law, including Copyright law. Copyright, IPR and Moral Rights for the works on this site are retained by the individual authors and/or other copyright owners. Terms and conditions for use of this material are defined in the policies page.

\section{CLoK}

Central Lancashire online Knowledge www.clok.uclan.ac.uk

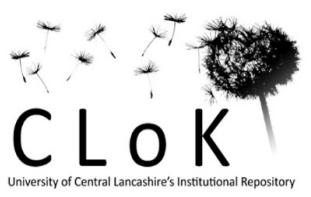




\title{
Caesarean section for non-medical reasons at term (Review)
}

\author{
Lavender T, Hofmeyr GJ, Neilson JP, Kingdon C, Gyte GML
}

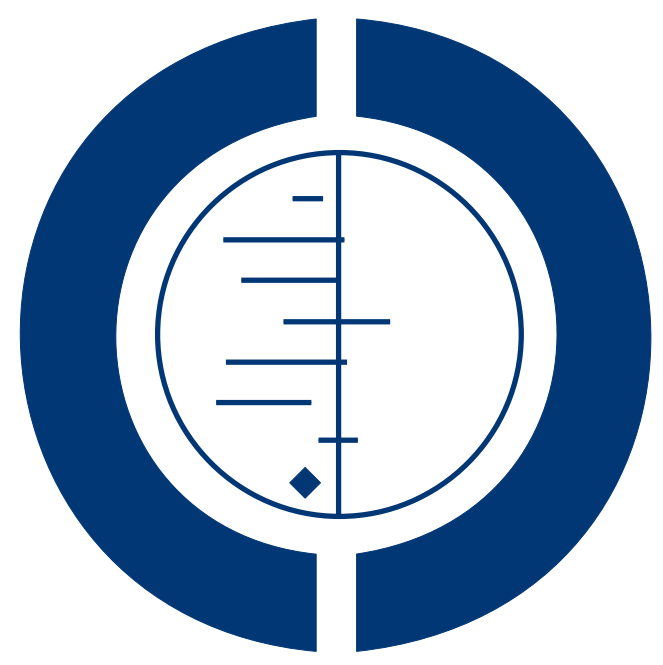

\section{THE COCHRANE COLLABORATION $^{\circledR}$}

This is a reprint of a Cochrane review, prepared and maintained by The Cochrane Collaboration and published in The Cochrane Library 2009, Issue 3

http://www.thecochranelibrary.com

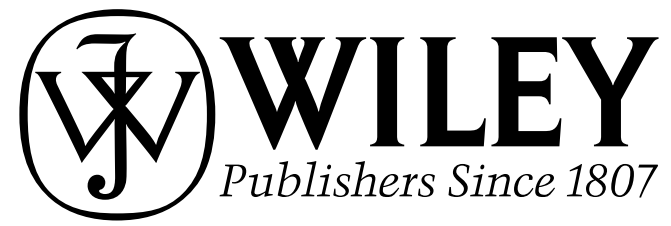

Caesarean section for non-medical reasons at term (Review)

Copyright (C) 2009 The Cochrane Collaboration. Published by John Wiley \& Sons, Ltd. 
TABLE OF CONTENTS

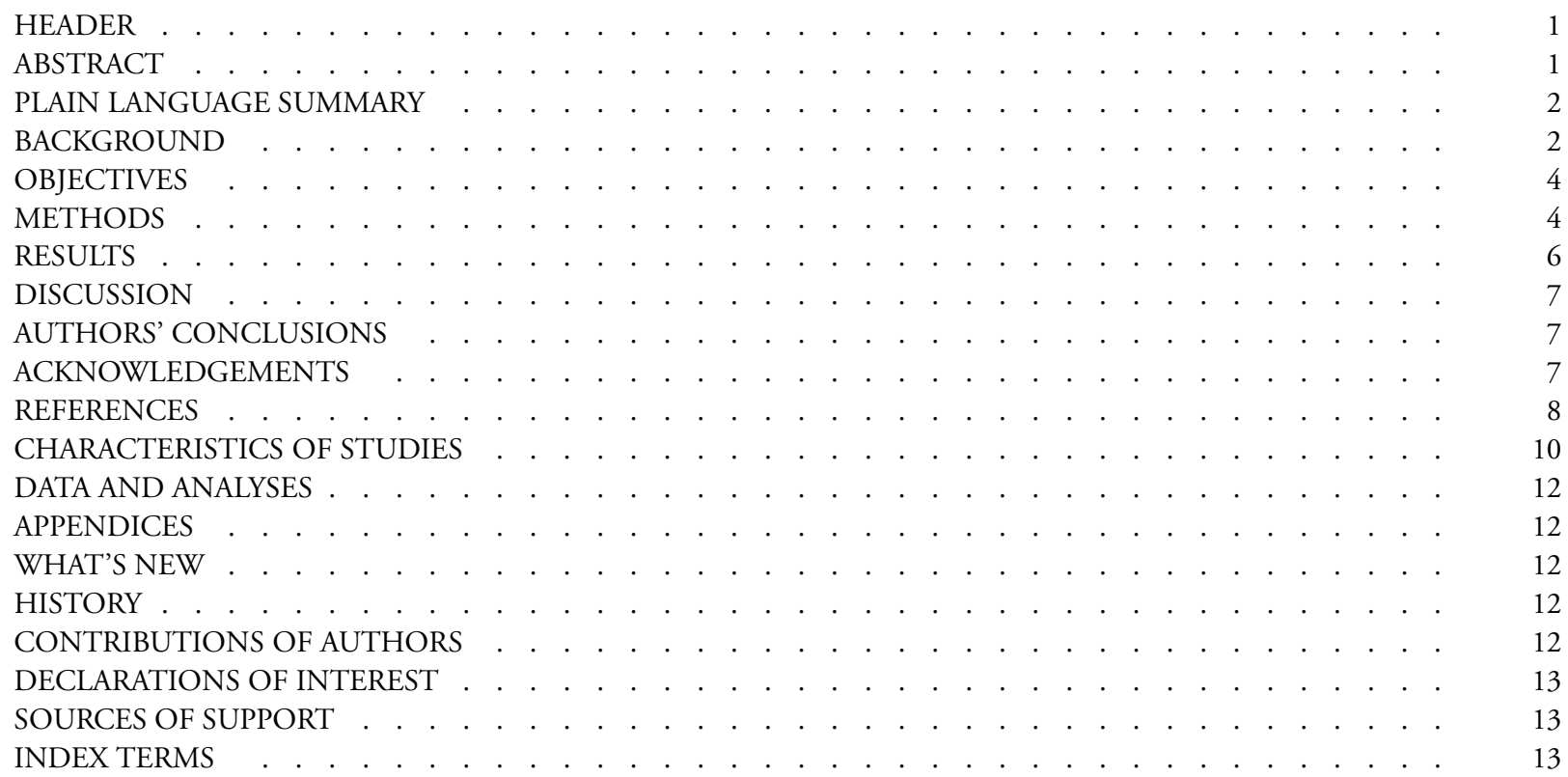

Caesarean section for non-medical reasons at term (Review)

Copyright @ 2009 The Cochrane Collaboration. Published by John Wiley \& Sons, Ltd. 


\title{
[Intervention Review]
}

\section{Caesarean section for non-medical reasons at term}

\author{
Tina Lavender ${ }^{1}$, G Justus Hofmeyr ${ }^{2}$, James P Neilson ${ }^{3}$, Carol Kingdon ${ }^{4}$, Gillian ML Gyte ${ }^{5}$ \\ ${ }^{1}$ School of Nursing, Midwifery and Social Work, The University of Manchester, Manchester, UK. ${ }^{2}$ Department of Obstetrics and \\ Gynaecology, East London Hospital Complex, University of the Witwatersrand, University of Fort Hare, Eastern Cape Department \\ of Health, East London, South Africa. ${ }^{3}$ School of Reproductive and Developmental Medicine, Division of Perinatal and Reproductive \\ Medicine, The University of Liverpool, Liverpool, UK. ${ }^{4}$ Midwifery Studies, University of Central Lancashire, Preston, UK. ${ }^{5}$ Cochrane \\ Pregnancy and Childbirth Group, School of Reproductive and Developmental Medicine, Division of Perinatal and Reproductive \\ Medicine, The University of Liverpool, Liverpool, UK \\ Contact address: Tina Lavender, School of Nursing, Midwifery and Social Work, The University of Manchester, Oxford Road, \\ Manchester, M13 9PL, UK. tina.lavender@manchester.ac.uk.
}

Editorial group: Cochrane Pregnancy and Childbirth Group.

Publication status and date: New search for studies and content updated (no change to conclusions), published in Issue 3, 2009.

Review content assessed as up-to-date: 27 April 2009.

Citation: Lavender T, Hofmeyr GJ, Neilson JP, Kingdon C, Gyte GML. Caesarean section for non-medical reasons at term. Cochrane Database of Systematic Reviews 2006, Issue 3. Art. No.: CD004660. DOI: 10.1002/14651858.CD004660.pub2.

Copyright (C) 2009 The Cochrane Collaboration. Published by John Wiley \& Sons, Ltd.

\section{A B S T R A C T}

\section{Background}

Caesarean section rates are progressively rising in many parts of the world. One suggested reason is increasing requests by women for caesarean section in the absence of clear medical indications, such as placenta praevia, HIV infection, contracted pelvis and, arguably, breech presentation or previous caesarean section. The reported benefits of planned caesarean section include greater safety for the baby, less pelvic floor trauma for the mother, avoidance of labour pain and convenience. The potential disadvantages, from observational studies, include increased risk of major morbidity or mortality for the mother, adverse psychological sequelae, and problems in subsequent pregnancies, including uterine scar rupture and greater risk of stillbirth and neonatal morbidity. An unbiased assessment of advantages and disadvantages would assist discussion of what has become a contentious issue in modern obstetrics.

\section{Objectives}

To assess, from randomised trials, the effects on perinatal and maternal morbidity and mortality, and on maternal psychological morbidity, of planned caesarean delivery versus planned vaginal birth in women with no clear clinical indication for caesarean section.

\section{Search strategy}

We searched the Cochrane Pregnancy and Childbirth Group's Trials Register (April 2009).

\section{Selection criteria}

All comparisons of intention to perform caesarean section and intention for women to give birth vaginally; random allocation to treatment and control groups; adequate allocation concealment; women at term with single fetuses with cephalic presentations and no clear medical indication for caesarean section.

\section{Data collection and analysis}

We identified no studies that met the inclusion criteria. 


\section{Main results}

There were no included trials.

\section{Authors' conclusions}

There is no evidence from randomised controlled trials, upon which to base any practice recommendations regarding planned caesarean section for non-medical reasons at term. In the absence of trial data, there is an urgent need for a systematic review of observational studies and a synthesis of qualitative data to better assess the short- and long-term effects of caesarean section and vaginal birth.

\section{PLAIN LANGUAGE SUMMARY}

\section{Caesarean section for non-medical reasons at term}

No trials to help assess the risks and benefits of caesarean section for women with no conventional medical indication for a caesarean.

Childbirth is a profound and powerful human experience. Women often describe feelings of empowerment, elation and achievement, although other women's experiences include trauma, fear, pain, and loss of control. The way women give birth, either vaginally or by caesarean section, is likely to impact on their feelings. In recent years, caesareans have become safer due to improved anaesthesia and improved surgical techniques, along with the routine use of drugs at surgery to combat the increased risk of infection and blood clots in the mother. However, caesarean section remains a surgical procedure accompanied by abdominal and uterine incisions, scarring and adhesions. This review found no trials to help assess the risks and benefits of caesarean section when undertaken without a conventional medical indication, and the authors strongly recommend alternative research methods to gather data on the outcomes associated with different ways of giving birth.

\section{B A C K G R O U N D}

Childbirth is a profound and powerful human experience. Women's accounts of birth often describe feelings of empowerment, elation and achievement, particularly following vaginal birth without medical interventions (Gaskin 2003); whereas other women associate childbirth with trauma, loss of control, fear, pain and anxiety. It is possible that the experience of giving birth may contribute to a woman's ability to adapt to parenthood, although there is only indirect evidence of this. Women giving birth in a supportive environment have been shown to have greater self-esteem, confidence in themselves as mothers, more positive child-rearing practices and less anxiety and depression after birth (Wolman 1993).

The term 'caesarean section' refers to the operation of delivering a baby through incisions made in the mother's abdominal wall and uterus. Performed for certain medical indications such as placenta praevia (placenta lying over the opening of the cervix) or transverse lie (the baby lying across the uterus), caesarean section can be a life-saving operation (Neilson 2003). A caesarean section is medically indicated when a significant risk of adverse outcome for mother or baby is present if the operation is not performed at a given time (Penna 2003). However, the use of caesarean section for more vague medical indications (failure to progress, presumed fetal compromise) and non-medical reasons (for example, maternal request) is increasing in many resource-rich health services. Non-medically indicated caesarean sections may be performed for reasons other than the risk of adverse outcome if the person(s) assessing risk feel it is outweighed by the physical or psychological benefits. It has been suggested, for example, that a proportion of women, who request caesarean section for no apparent medical reason, may actually have been influenced by previous or current psychological trauma (Ryding 1993) such as sexual abuse or a previous traumatic birth. These may legitimately be regarded as clinical indications.

In the UK, caesarean section accounted for $2 \%$ of all births in $1953,18 \%$ in 1997 (Macfarlane 2000) and 21\% in 2001(Thomas 2001). Whilst there has been a world-wide trend towards increasing caesarean section rates (CSR), rates vary considerably within and between countries. In Norway, wide variations in CSRs (between $6 \%$ and 20\%) have been reported between obstetric departments (Bergen 2002). In the United States of America, figures from alternative birth settings show considerably lower CSRs (1.5\% - Gaskin 2003) than the national average (24.4\% - Martin 2002). Furthermore, marked differences are reported in rates from 
different healthcare sectors. During a two-year period in an urban area of India, total CSRs in the public, charitable and private sectors were $20 \%$, 38\% and 47\% respectively (Sreevidya 2003).

The extent to which women's request for caesarean section for non-medical reasons has contributed to these rates, and why, is a contentious issue (Goer 2001; Lowdon 2002; McAleese 2000; Paterson-Brown 1998; Sultan 1996). Existing evidence from both retrospective and prospective studies is limited, utilising different definitions of 'maternal request', and reporting rates of between $1 \%$ and $48 \%$ in public sector healthcare systems, and $60 \%$ in the private sector (Declerq 2002; Thomas 2001). There is insufficient understanding as to why women may request a caesarean section in the absence of a medical reason. Two systematic literature reviews have highlighted specific methodological, conceptual (Gamble 2000) and cultural issues (Kingdon 2006) that may influence women's preferences for vaginal or caesarean birth in different populations. Women's previous birth experience, fear of vaginal birth, need for choice and control, coupled with the cultural acceptability of caesarean section may all influence women's decision-making surrounding ways of giving birth. Whilst it is likely that the role of the caregiver in data generation, timing of data collection, women's post-hoc rationalisation and recall bias, have led to the over-reporting of maternal request for caesarean section, nonetheless, a percentage of women are now undergoing caesarean section for non-medical reasons. Informed decision-making for both clinicians and women is dependent on accurate information about the consequences of caesarean section compared with vaginal birth.

In countries where the caesarean section rate is rising, the incidence of vaginal birth is, as expected, in decline. Intervention in the physiological processes of 'normal' birth varies according to birth setting. In high intervention birth settings where the use of artificial oxytocin, electronic fetal monitoring, epidural analgesia, artificially ruptured membranes, and instrumental deliveries are common, the extent to which adverse outcomes attributed to vaginal birth may also be associated with current obstetric management is an issue. The use of forceps may be particularly relevant to the debate on the possible maternal benefits of caesarean delivery increasingly being cited as including the protection of the pelvic floor to avoid perineal pain, dyspareunia, uterovaginal prolapse and incontinence of urine, flatus and/or faeces (Farrell 2001; Rortveit 2003; Sultan 1993; Sultan 1994; Sultan 1996; Sultan 1997).

Other possible benefits of elective caesarean section discussed in both the professional and lay press include the convenience of scheduling the time and date of delivery (Kirby 1999; Wagner 2000). The extent to which convenience is cited as a maternal benefit may be confounded by the convenience for caregivers. The opportunity to schedule caesarean sections enables caregivers to plan staffing levels accordingly, performing the caesarean sections within daylight hours, and possibly reduce the incidence of litigation associated with vaginal birth or emergency caesareans (Birchard 1999). Avoidance of pain during labour has also been cited as a potential maternal benefit of elective caesarean delivery (Turnbull 1999); as has the avoidance of emergency caesarean sections during labour, which has been associated with increases in morbidity and mortality (Lilford 1990; Paterson-Brown 1998). Precise assessments of the mortality risks associated with elective caesarean section for non-medical reasons are problematic due to multiple definitions of 'elective', and a lack of up-todate data which distinguishes between outcomes from scheduled or emergency caesarean sections. Nevertheless, Hall and Bewley (Hall 1999) have calculated the case-fatality rate for elective caesarean section in the UK during 1994 to 1996 and estimate it to be almost three times as great as that for vaginal births.

The benefit-risk calculus associated with surgery has evolved, as techniques for surgery, anaesthesia, infection control, and blood banking have improved (Minkoff 2003). Nonetheless, there is evidence to suggest increased maternal risks associated with the surgery, including anaesthetic risks, surgical complications, increased blood loss, need for transfusion, and pulmonary embolism (Kelleher 1994). There may also be restricted activities of daily living (Chippington 2004), breastfeeding difficulties (Francome 1993) and increased maternal problems related to the uterine scar in subsequent pregnancies (Hemminki 1996). A retrospective cohort study of 308,755 Canadian women who had experienced a previous caesarean section found trial of labour is associated with increased risk of uterine rupture $(0.65 \%$ in the trial of labour group compared to $0.25 \%$ in the non-trial of labour group), but elective caesarean section may increase the risk of maternal death (1.6 per 100,000 in the trial of labour group compared to 5.6 per 100,000 in the elective caesarean section group (Wen 2004). Furthermore new, unexpected long-term risks of caesarean section continue to be reported; these include abnormal placentation (Serena 2005), ectopic pregnancy, haemorrhage and hysterectomy following uterine evacuation, latex allergy, implantation endometriosis, adenomyosis and increased hospital readmission (Bewley 2002). Caesarean section has also been associated with emotional difficulties (Clement 2001) including postpartum depression and negative feelings about the experience of childbirth, but not specifically among women undergoing caesarean delivery by choice (Minkoff 2003). Suggested increased risks for the baby of delivery by caesarean section include, increased admission to neonatal units/separation of the mother and neonate (Treffers 1993), iatrogenic prematurity (Wagner 2000), laceration (Smith 1997), increased neonatal respiratory problems (Madar 1999) and stillbirth in the next pregnancy (Smith 2003).

In a large multi-centre randomised controlled trial of planned caesarean section versus planned vaginal birth for breech presentation, at three months postnatally, women in the planned caesarean delivery group were less likely to report urinary incontinence (Hannah 2002). There was no statistically significant difference regarding 
incontinence of flatus between groups, but more women reported that it was less of a problem in the planned caesarean delivery group. At three months there were no differences between groups in breastfeeding; infant health; ease of caring for infant and adjusting to being a new mother; sexual relations; pain; depression; and views regarding childbirth experience. The trial reported a significant reduction in adverse perinatal outcomes without an increased risk of immediate maternal morbidity with planned caesarean section compared with planned vaginal birth. The two-year follow up of the same trial (Hannah 2004) showed no differences between groups in breastfeeding; relationship with child or partner; pain; subsequent pregnancy; incontinence; depression; urinary, menstrual or sexual problems; fatigue; or distressing memories of the birth experience. Planned caesarean section was associated with a higher risk of constipation. There was no difference identified between planned caesarean section and planned vaginal birth in risk of death or neurodevelopmental delay in children at two years of age (Whyte 2004). This finding was surprising, given the reduction in the risk of perinatal or neonatal death, or serious neonatal morbidity, with a policy of planned caesarean birth found at three months. The applicability of these findings for cephalic presentation is debatable.

Maternal and neonatal physical health outcomes must also be considered alongside psychosocial influences and the wider cultural context. For example, the trend towards smaller families may be relevant when considering the risks of caesarean section for subsequent pregnancies. The increasingly cited risks of vaginal birth such as placental abruption, cord prolapse, undiagnosed fetal hypoxaemia and shoulder dystocia (Paterson-Brown 1997) must be considered in the context of the medical model within technologydependent cultures where intervention in the natural processes of reproduction is common. For many healthcare systems, the economic costs associated with different modes of delivery are as pertinent as the social costs. A recent economic model, developed to determine the cost consequence of planned caesarean section in the absence of medical indication to the NHS, estimated it to range from $£ 10.9$ to $£ 14.8$ million per annum. The mean cost saving of switching from a planned caesarean section to a planned vaginal birth was $£ 1257$ per birth (NCCWCH 2004). However, in the USA it would appear the costs of increased intervention in vaginal deliveries, the addition of oxytocin specifically, can nullify any cost differences between delivery mode. If epidural anaesthesia is also used, total costs exceeded the cost of elective caesarean delivery by almost $10 \%$ in one study (Bost 2003).

Caesarean section for non-medical reasons is a multifaceted complex issue, the implications of which for childbearing women, healthcare professionals and society are unknown. For women, requesting a caesarean section for non-medical reasons is an emotive and very personal decision. For clinicians, performing a caesarean section for non-medical reasons is a professional decision, the ethics of which are being debated without sufficient evidence of the risks, as well as the benefits. The review aims to assist women and clinicians to make informed evidence-based decisions about the way women give birth.

\section{O B J E C T I V E S}

To assess, from randomised trials, the effects on perinatal and maternal morbidity and mortality, and on maternal psychological morbidity, of planned caesarean delivery versus planned vaginal birth where there is no clear clinical indication for a caesarean section.

\section{METHODS}

\section{Criteria for considering studies for this review}

\section{Types of studies}

All comparisons of intention to perform caesarean section and intention to give birth vaginally; random allocation to treatment and control groups; violations of allocated management and exclusions after allocation not sufficient to materially affect outcomes. Given the nature of the review objective, we planned to include observational and qualitative research in the discussion, to place any trial findings in a social, cultural, organisational, and geographical context.

\section{Types of participants}

Pregnant women, singleton pregnancy, cephalic presentation at term, with no conventional medical indication for caesarean section. Data on the consequences of planned caesarean section for breech presentation, previous caesarean section and twins are medical indications and are reviewed separately ('Planned caesarean section for term breech delivery' (Hofmeyr 2003), 'Planned elective repeat caesarean section versus planned vaginal birth for women with a previous caesarean birth' (Dodd 2004), 'Planned caesarean section for multiple pregnancy' (Dodd 2002)).

\section{Types of interventions}

Planned caesarean section compared with planned vaginal birth in the absence of a medical reason for caesarean section (non-medical reason as defined by trial authors). 


\section{Types of outcome measures}

\section{Outcomes for mother}

\section{Short-term maternal outcomes}

1. Serious maternal morbidity or death (e.g. admission to intensive care unit, septicemia, organ failure);

2. caesarean section (emergency/elective);

3. regional analgesia;

4. general anaesthesia;

5. complications of anaesthesia (anaphylaxis, inhalation of gastric contents, dural tap);

6. instrumental vaginal birth;

7. postpartum haemorrhage (as defined by the trial authors);

8. postpartum anaemia (as defined by the trial authors);

9. blood transfusion;

10. hysterectomy;

11. deep venous thrombosis and pulmonary embolism;

12. postpartum pyrexia (infection, wound, bladder, perineum, genital tract, chest, haematoma: wound, perineum);

13. other operative postpartum interventions (evacuation of retained products of conception, evacuation of haematoma, wound/episiotomy repair);

14. antibiotic use;

15. antithrombotic prophylaxis;

16. experience of childbirth.

\section{Long-term maternal outcomes}

1. Postnatal depression (as defined by trial authors);

2. breastfeeding failure (as defined by trial authors);

3. perineal pain;

4. abdominal pain;

5. backache;

6. other pain;

7. dyspareunia (as defined by trial authors);

8. uterovaginal prolapse;

9. urinary incontinence;

10. flatus incontinence;

11. faecal incontinence;

12. postnatal self-esteem (as defined by trial authors);

13. postnatal anxiety (as defined by trial authors);

14. post traumatic stress syndrome;

15. relationship with partner;

16. relationship with baby (as defined by trial authors);

17. subsequent pregnancy complications (ectopic pregnancy, abruption, placenta praevia, placenta accreta, decreased fertility, miscarriage, hysterectomy, major obstetric haemorrhage);

18. postpartum rehospitalisation;

19. experience of childbirth.

\section{Outcomes for baby}

1. Serious neonatal morbidity or perinatal death, excluding fatal malformations (e.g. seizures, birth asphyxia defined by trialists, neonatal encephalopathy, disability in childhood);

2. preterm birth;

3. asthma;

4. behavioural/learning disorders;

5. Apgar score less than seven at five minutes;

6. cord blood $\mathrm{pH}$ less than 7.2;

7. neonatal intensive care unit admission;

8. neonatal encephalopathy (as defined by trial authors);

9. brachial plexus injury;

10. transient tachypnea of the newborn; hyaline membrane disease/surfactant/continuous positive airways pressure/ ventilation;

11. jaundice;

12. febrile illness/sepsis;

13. physical infant trauma (e.g. cuts and bruises);

14. disability in childhood.

\section{Health services}

1. Caregiver experience;

2. cost: time, financial, staffing, facilities, training.

Outcomes were to be included if considered clinically meaningful by trial authors; reasonable measures taken to minimise observer bias; missing data insufficient to materially influence conclusions; data available for analysis according to original allocation, irrespective of protocol violations; data available in format suitable for analysis.

\section{Search methods for identification of studies}

\section{Electronic searches}

We searched the Cochrane Pregnancy and Childbirth Group's Trials Register by contacting the Trials Search Co-ordinator (April 2009)

The Cochrane Pregnancy and Childbirth Group's Trials Register is maintained by the Trials Search Co-ordinator and contains trials identified from:

1. quarterly searches of the Cochrane Central Register of Controlled Trials (CENTRAL);

2. weekly searches of MEDLINE;

3. handsearches of 30 journals and the proceedings of major conferences;

4. weekly current awareness alerts for a further 44 journals plus monthly BioMed Central email alerts.

Details of the search strategies for CENTRAL and MEDLINE, the list of handsearched journals and conference proceedings, and the list of journals reviewed via the current awareness service can 
be found in the 'Specialized Register' section within the editorial information about the Cochrane Pregnancy and Childbirth Group.

Trials identified through the searching activities described above are each assigned to a review topic (or topics). The Trials Search Co-ordinator searches the register for each review using the topic list rather than keywords.

We did not apply any language restrictions.

For details of searching carried out for the previous version of the review, please see Appendix 1.

\section{Data collection and analysis}

We used the standard methods of The Cochrane Collaboration as described in the Cochrane Reviewers' Handbook (Alderson 2004). Three review authors (T Lavender, C Kingdon, G Gyte) assessed the trials under consideration for appropriateness of inclusion and methodological quality with the aid of a study eligibility form, developed specifically for the purposes of this review. Any differences of opinion would have been resolved by discussion with the remaining two review authors (GJ Hofmeyr, JP Neilson): there were no differences of opinion requiring resolution. Blinding of trial authorship and results were not undertaken.

\section{Assessment of trial quality}

Three major sources of potential bias (and methods of avoidance of these biases) were to be considered when assessing trial quality: (1) selection bias - allocation concealment; (2) attrition bias - completeness of follow up; (3) detection bias - blinding of outcome assessment. The quality assessment was based on a systematic assessment of the opportunity for each of these biases to arise.

We planned to assign a quality rating (of (A) yes, (B) unclear, or (C) no) to all trial components (random allocation, participant eligibility, intervention (planned caesarean section versus planned vaginal birth), completeness of follow up and inclusion of outcomes (as defined by review authors). Where information was unclear within papers, we attempted to contact corresponding trial authors. Trials from the review with a 'B' or 'C' rating for any of the quality ratings were subsequently excluded.

\section{Data management and analysis}

We would have used data extraction forms that included information regarding study location, methods, participant characteristics at baseline, details of the intervention and control group management and outcome. All review authors would have extracted the data and disagreements would have been resolved by discussion. We would have sought missing data from investigators of individual trials as necessary in order to perform analyses on an intentionto-treat basis. We planned to undertake double-data entry.
We planned to report mean differences (and 95\% confidence intervals) for continuous variables. For categorical outcomes, we intended to report the risk ratio and risk difference (and 95\% confidence intervals). For the meta-analysis, where possible, we planned to report mean differences (and 95\% confidence intervals) for continuous variables, and the risk ratio and risk difference (and $95 \%$ confidence intervals) for categorical outcomes. We intended to calculate the number needed to treat where appropriate.

We planned to undertake a priori subgroup analyses, as data permitted, as follows:

1. nulliparous and multiparous;

2. services with low (20 or less per 1000) and high perinatal mortality (more than 20 );

3. natural conception and assisted conception;

4. low-level intervention in the first stage of labour in at least $75 \%$ versus less than $75 \%$ in the planned vaginal birth group;

5. low-level intervention in the first stage of labour, defined as spontaneous onset without regional anaesthesia - epidural, spinal or combination of the two (Birth Choice UK 2001).

\section{RES U L T S}

\section{Description of studies}

See: Characteristics of excluded studies.

The search strategies yielded two studies for consideration of inclusion (see'Characteristics of excluded studies'). However, neither of these studies met the basic inclusion criteria and were therefore excluded. One study (European Mode 1999) only included women with confirmed diagnosis of HIV-1 infection, which is a medical, as opposed to a 'non-medical', indication for caesarean section. Furthermore, it is unclear from the data how many participants had singleton pregnancies, cephalic presentations, term babies or complications of pregnancy, as the decision to randomise was at the clinician's discretion. The remaining study (Pence 2002) was excluded because of the potential for selection bias; the demography and parity of the sample and method of randomisation was unclear. We attempted to contact the author of this paper, to clarify these issues, without success.

\section{Risk of bias in included studies}

No studies met the eligibility criteria for inclusion in this review.

\section{Effects of interventions}

No studies met the eligibility criteria for inclusion in this review. 


\section{DISCUSSION}

There are no randomised controlled trials of planned caesarean section versus planned vaginal birth for non-medical reasons at term, which makes the comparability of the effects on perinatal and maternal morbidity and mortality, and maternal psychological morbidity, for these two different ways of giving birth problematic.

The need for evidence of the effects of caesarean section performed for non-medical reasons at term on perinatal and maternal mortality, and maternal psychological morbidity, is important to women and clinicians. The actual number of women requesting caesarean birth in the absence of clear indications for themselves or their baby is unknown (Klein 2004). However, a proportion of women are currently undergoing caesarean section performed for nonmedical reasons at term, whilst existing evidence concerning the risks and benefits is keenly contested by professionals (Minkoff 2003) and consumer organisations representing maternity service users (Lowdon 2002).

Informed decision-making surrounding vaginal or caesarean birth is considered by some to be aided in specific situations, where randomised controlled trials have been performed and systematically reviewed. For example, planned caesarean section for term breech delivery (Hofmeyr 2003), or planned elective repeat caesarean section versus planned vaginal birth for women with a previous caesarean birth (Dodd 2004).

The findings of existing trials of planned caesarean section performed for medical indications versus planned vaginal birth are not applicable to situations where there are no medical reasons, because caesarean mortality and morbidity is confounded by preexisting obstetric or general medical conditions (that is, European Mode 1999). The use of data from observational studies of planned caesarean for non-medical reason and planned vaginal birth seems at present inconclusive. For example, in the UK, the most recent data suggest that the estimated case fatality rate per million maternities and risk ratio for elective caesarean section were twice that for vaginal birth. However, this was not statistically significant and "it cannot be concluded that caesarean section is necessarily more dangerous than vaginal birth" (Hall 2001); particularly as the number of elective caesarean sections performed for medical indications was unclear.

The extent to which performing a randomised controlled trial of planned caesarean section for non-medical reasons versus planned vaginal birth would provide sufficient evidence to assess the risks and benefits of all relevant outcomes is debatable (Mccourt 2004). Furthermore, to discuss the possibility of such a trial not only raises important methodological questions, but also introduces significant moral concerns about the ethics of undertaking a trial where women randomised to the intervention arm would receive surgery in the absence of a medical indication.

\section{AUTHORS' CONCLUSIONS}

\section{Implications for practice}

There is no evidence from randomised controlled trials upon which to base any practice recommendations regarding planned caesarean section for non-medical reasons at term.

\section{Implications for research}

Although a number of trials have assessed the efficacy of planned vaginal birth versus planned caesarean section, sample populations have included women with potential (Barrett 2004; Dodd 2004; Hannah 2000) or actual pregnancy complications (European Mode 1999). Planned caesarean section for non-medical reasons at term is more contentious because it involves a surgical procedure where there is neither a medical problem nor any complications. The lack of existing evidence is likely to be due to the lack of equipoise for such a trial or the highly complex methodological issues which such a trial may generate (Lavender 2005). These include the complexity of following up women throughout their reproductive life; the difficulty of agreeing on a single primary outcome on which to base sample-size calculations; and the prohibitive cost of a trial in relation to more pertinent research questions. The routine collection of good quality prospective morbidity data (short and long term) may provide the best available evidence from which women can make informed decisions. Qualitative explorations which contextualise maternal and professional views and experiences would also add to the evidence base. In the absence of trial data, there is an urgent need for a systematic review of observational studies and a synthesis of qualitative data to better assess the short- and long-term outcomes of caesarean section and vaginal birth.

\section{ACKNOWLEDGEMENTS}

As part of the pre-publication editorial process, this review has been commented on by three peers (an editor and two referees who are external to the editorial team), one or more members of the Pregnancy and Childbirth Group's international panel of consumers and the Group's Statistical Adviser. 


\section{REFERENCES}

\section{References to studies excluded from this review}

\section{European Mode 1999 \{published data only\}}

The European Mode of Delivery Collaboration. Elective caesarean section versus vaginal delivery in prevention of vertical HIV-1 transmission: a randomised clinical trial. Lancet 1999;353:1035-9.

\section{Pence 2002 \{published data only\}}

Pence S, Kocoglu H, Balat O, Balat A. The effect of delivery on umbilical arterial cord blood gases and lipid peroxides: comparison of vaginal delivery and caesarean section. Clinical and Experimental Obstetrics and Gynecology 2002;3 $212-4$

\section{Additional references}

\section{Alderson 2004}

Alderson P, Green S, Higgins JPT, editors. Cochrane Reviewers' Handbook 4.2.2 [updated March 2004]. In: The Cochrane Library, Issue 1, 2004. Chichester, UK: John Wiley \& Sons, Ltd.

\section{Barrett 2004}

Barrett J. Twin Birth Study Protocol. www.utoronto.ca/ miru. Maternal, Infant and Reproductive Health Research Unit, University of Toronto, (accessed 3 May 2006).

\section{Bergen 2002}

Annual Report 1999-2000. Bergen Medical Birth Registry of Norway 2002.

\section{Bewley 2002}

Bewley S, Cockburn J. The unfacts of request caesarean section. BJOG: an international journal of obstetrics and gynaecology 2002;109:597-605.

\section{Birchard 1999}

Birchard K. Defence union suggest new approach to handling litigation costs in Ireland. Lancet 1999;354:1710.

\section{Birth Choice UK 2001}

Birth Choice UK. Normal birth rates: England. www.normalbirth@birthchoiceuk.com (accessed 17 November 2003).

\section{Bost 2003}

Bost BW. Cesarean delivery on demand: what will it cost?. American Journal of Obstetrics and Gynecology 2003;188(6): 1418-23.

\section{Chippington 2004}

Chippington Derrick D, Lowdon G, Barlow F. Caesarean birth: your questions answered. London: National Childbirth Trust, 2004.

\section{Clement 2001}

Clement S. Psychological aspects of caesarean section. Baillieres Best Practice and Research. Clinical Obstetrics and Gynaecology 2001;15(1):109-26.

\section{Declerq 2002}

Declercq ER, Sakala C, Corry MP, Applebaum S, Risher P. Listening to mothers: report of the first national US survey of women's childbearing experiences. New York: Maternity Center Association, October 2002.

\section{Dodd 2002}

Dodd JM, Crowther CA. Elective delivery of women with a twin pregnancy from 37 weeks' gestation. Cochrane Database of Systematic Reviews 2002, Issue 2. [DOI: 10.1002/14651858.CD003582]

\section{Dodd 2004}

Dodd J, Crowther CA, Huertas E. Planned elective repeat caesarean section versus planned vaginal birth for women with a previous caesarean birth. Cochrane Database of Systematic Reviews 2004, Issue 4. [DOI: 10.1002/ 14651858.CD004224.pub2]

\section{Farrell 2001}

Farrell SA, Allen VM, Baskett TF. Parturition and urinary incontinence in primiparas. Obstetrics \& Gynecology 2001; 97:350-6.

\section{Francome 1993}

Francome C, Savage W, Churchill H, Lewison H. Caesarean birth in Britain. London: Middlesex University Press, 1993.

\section{Gamble 2000}

Gamble J, Creedy DK. Women's request for cesarean section: a critique of the literature. Birth 2000;27:256-63.

\section{Gaskin 2003}

Gaskin IM. Ina May's guide to childbirth. 1st Edition. New York: Bantam Dell, 2003.

\section{Goer 2001}

Goer $\mathrm{H}$. The case against elective cesarean section. Journal of Perinatal and Neonatal Nursing 2001;15(3):23-38.

Hall 1999

Hall MH, Bewley S. Maternal mortality and mode of delivery. Lancet 1999;354:776.

\section{Hall 2001}

Hall M. Why mothers die 1997-1999: the confidential enquiries into maternal deaths in the United Kingdon. 5th Report of the National Confidential Enquiries. London: RCOG, 2001.

\section{Hannah 2000}

Hannah ME, Hannah WJ, Hewson S, Hodnett E, Saigal $S$, Willan A. Planned caesarean section versus planned vaginal birth for breech presentation at term: a randomised multicentre trial. Lancet 2000;356:1375-83.

\section{Hannah 2002}

Hannah ME, Hannah WJ, Hodnett ED, Chalmers B, Kung $\mathrm{R}$, William A. Outcomes at 3 months after planned cesarean vs planned vaginal delivery for breech presentation at term. JAMA 2002;287(14):1822-31.

\section{Hannah 2004}

Hannah ME, Whyte H, Hannah WJ, Hewson S, Amankwah K, Cheng M, et al.Maternal outcomes at 2 years after planned cesarean section versus planned vaginal birth for breech presentation at term: the international 
randomized term breech trial. American Journal of Obstetrics and Gynecology 2004;191:917-27.

\section{Hemminki 1996}

Hemminki E, Merilainen J. Long-term effects of cesarean sections: ectopic pregnancies and placental problems. American Journal Obstetrics and Gynecology 1996;174: 569-74.

\section{Hofmeyr 2003}

Hofmeyr GJ, Hannah ME. Planned caesarean section for term breech delivery. Cochrane Database of Systematic Reviews 2003, Issue 2. [DOI: 10.1002/ 14651858.CD000166]

\section{Kelleher 1994}

Kelleher CJ, Cardozo LD. Caesarean section: a safe operation?. Journal of Obstetrics and Gynaecology 1994;14: 86-90.

\section{Kingdon 2006}

Kingdon C, Baker L, Lavender T. Systematic review of nulliparous women's views of planned cesarean birth: the missing component in the debate about a term cephalic trial. Birth 2006; Vol. 33, issue 3:229-37.

\section{Kirby 1999}

Kirby RS, Hanlon-Lundberg KM. Cesarean delivery: improving on nature?. Birth 1999;26(4):259-62.

\section{Klein 2004}

Klein MC. Quick fix culture: the caesarean section on demand debate. Birth 2004;31(3):161-4.

\section{Lavender 2005}

Lavender T, Kingdon C, Hart A, Gyte G, Gabbay MB, Neilson JP. Could a randomised trial answer the elective caesarean section controversy? A national survey of consultant obstetricians and heads of midwifery. BMJ 2005; 331:490-1.

\section{Lilford 1990}

Lilford RJ, van Coeverden de Groot HA, Moore PJ, Bingham P. The relative risks of caesarean section (intrapartum and elective) and vaginal delivery: a detailed analysis to exclude the effects of medical disorders and other acute pre-existing physiological disturbances. British Journal of Obstetrics and Gynaecology 1990;97:883-92.

\section{Lowdon 2002}

Lowdon G, Derrick D. Caesarean section or vaginal birth - what difference does it make?. AIMS Quarterly Journal 2002;14(1):1-4.

Macfarlane 2000

Macfarlane A, Mugford M, Henderson J, Furtado A, Stevens K, Dunn A. Birth counts: statistics of pregnancy and childbirth. Vol. 2, London: Stationery office, 2000.

\section{Madar 1999}

Madar JJ, Richmond S, Hey E. Hyaline membrane disease after elective delivery at term. Acta Paediatrica 1999;88: $1244-84$.

Martin 2002

Martin JA, Hamilton BE, Ventura SJ, Menacker F, Park M, Sutton PD. Births: final data for 2001. National Vital Statistics Reports 2002;51(2):1-102.
McAleese 2000

McAleese S. Caesarean section for maternal choice?

Midwifery Matters 2000;84:12-4.

Mccourt 2004

Mccourt C, Bick D, Weaver J. Caesarean section: perceived demand. British Journal of Midwifery 2004;12(7):412-4.

\section{Minkoff 2003}

Minkoff $\mathrm{H}$, Chervenak FA. Elective primary cesarean delivery. New England Journal of Medicine 2003;348(10): 946-50.

\section{NCCWCH 2004}

The National Collaborating Centre for Women's and Childrens Health. Caesarean section clinical guideline. London: RCOG Press, April 2004.

\section{Neilson 2003}

Neilson JP. Interventions for suspected placenta praevia. Cochrane Database of Systematic Reviews 2003, Issue 1. [DOI: 10.1002/14651858.CD001998]

\section{Paterson-Brown 1997}

Paterson-Brown S, Fisk NM. Caesarean section: every woman's right to choose?. Current Opinion in Obstetrics \& Gynecology 1997;9:351-5.

\section{Paterson-Brown 1998}

Paterson-Brown S. Should doctors perform an elective caesarean section on request? Yes, as long as the woman is fully informed. BMJ 1998;317:462-5.

\section{Penna 2003}

Penna L, Arulkumaran S. Cesarean section for non-medical reasons. International Journal of Gynaecology \& Obstetrics 2003;82:399-409.

\section{Rortveit 2003}

Rortveit G, Daltveit AK, Hannestad YS, Hunskaar S. Urinary incontinence after vaginal delivery or cesarean section. New England Journal of Medicine 2003;348(10): 900-7.

\section{Ryding 1993}

Ryding EL. Investigation of 33 women who demanded caesarean section for personal reasons. Acta Obstetricia et Gynecologica Scandinavica 1993;72:280-5.

Serena 2005

Serena W, Kocherginsky M, Hibbard JU. Abnormal placentation: twenty-year analysis. American Journal of Obstetrics and Gynaecology 2005;192:1458-61.

\section{Smith 1997}

Smith JF, Hernandez C, Wax JR. Fetal laceration injury at cesarean delivery. Obstetrics \& Gynecology 1997;90(3): 344-6.

\section{Smith 2003}

Smith GC, Pell JP, Dobbie R. Caesarean section and risk of unexplained stillbirth in subsequent pregnancy. Lancet 2003;362:1779-84.

\section{Sreevidya 2003}

Sreevidya S, Sathiyasekaran BWC. High caesarean rates in Madras (India): a population-based cross-sectional study. 
BJOG: an international journal of obstetrics and gynaecology 2003;110:106-11.

\section{Sultan 1993}

Sultan AH, Kamm MA, Hudson CN, Thomas JM, Bartram CI. Anal sphincter disruption during vaginal delivery. New England Journal of Medicine 1993;329:1905-11.

\section{Sultan 1994}

Sultan AH, Kamm MA, Hudson CN, Bartram CI. Third degree obstetric anal sphincter tears: risk factors and outcome of primary repair. BMJ 1994;308:887-91.

\section{Sultan 1996}

Sultan AH, Stanton SL. Preserving the pelvic floor and perineum during childbirth - elective caesarean section? . British Journal of Obstetrics and Gynaecology 1996;103: 731-4.

\section{Sultan 1997}

Sultan AH, Monga AK. Anal and urinary incontinence in women with obstetric anal sphincter rupture. British Journal of Obstetrics and Gynaecology 1997;104:754.

\section{Thomas 2001}

Thomas J, Paranjothy S, Royal College of Obstetricians \& Gynaecologists, Clinical Effectiveness Support Unit. The National Sentinel Caesarean Section Audit Report. London: RCOG Press, 2001.

\section{Treffers 1993}

Treffers PE, Pel M. The rising trend for caesarean birth. BMJ 1993;307:1017-8.

\section{Turnbull 1999}

Turnbull DA, Wilkinson C, Yaser A, Carty V, Svigos JM, Robinson JS. Women's role and satisfaction in the decision to have a caesarean section. Medical Journal of Australia 1999;170:580-3.

Wagner 2000

Wagner M. Choosing caesarean section. Lancet 2000;356: 1677-80.

Wen 2004

Wen SW, Rusen ID, Walker M, Listen R, Kramer MS, Baskett $\mathrm{T}$, et al.Comparison of maternal mortality and morbidity between trial of labour and elective cesarean section among women with previous caesarean delivery. American Journal of Obstetrics and Gynecology 2004;191: 1263-9.

\section{Whyte 2004}

Whyte H, Hannah ME, Saigal S, Hannah WJ, Hewson S, Amankwah K, et al.Outcomes of children at 2 years after planned caesarean birth versus planned vaginal birth for breech presentation at term: the international randomized term breech trial. American Journal of Obstetrics and Gynecology 2004;191:864-71.

\section{Wolman 1993}

Wolman WL, Chalmers B, Hofmeyr GJ, Nikoden VC. Postpartum depression and companionship in the clinical birth environment: a randomised controlled study. American Journal of Obstetrics and Gynecology 1993;168: 1388-93.

* Indicates the major publication for the study 
CHARACTERISTICS OF STUDIES

Characteristics of excluded studies [ordered by study ID]

\begin{tabular}{ll}
\hline Study & Reason for exclusion \\
\hline European Mode 1999 & $\begin{array}{l}\text { Pregnant women with confirmed diagnosis of HIV-1 infection were randomly assigned to planned caesarean } \\
\text { section }(\mathrm{n}=188) \text { at } 38 \text { weeks of pregnancy or vaginal birth }(\mathrm{n}=220) \\
\text { Three of } 170 \text { infants born to women assigned caesarean section delivery were infected compared with } 21 \text { of } \\
200 \text { born to women assigned vaginal delivery P < } 0.001\end{array}$ \\
& $\begin{array}{l}\text { This study was excluded as confirmed diagnosis of HIV-1 infection is a conventional indication for cae- } \\
\text { sarean section. Furthermore, it is unclear from the data how many participants had singleton pregnancies, } \\
\text { cephalic presentations or term babies: "for women with a previous caesarean section twin pregnancy, breech } \\
\text { presentation, intrauterine growth retardation or vaginal infection, e.g. active herpes infection, the decision } \\
\text { to randomise was at the clinicians discretion" }\end{array}$ \\
\hline $\begin{array}{l}\text { Pregnant women between } 37 \text { and } 42 \text { weeks' gestation were randomly assigned to one of three groups: group } 1 \\
\text { (n }=40) \text { were vaginally delivered, group } 2 \text { (n }=26) \text { had caesarean section with epidural anaesthesia, and group } \\
3 \text { (n }=30) \text { had caesarean section under general anaesthesia. The primary outcome measure was umbilical } \\
\text { arterial PO2 which was found to be higher in group } 3 \\
\text { The study was excluded because of the potential for selection bias; it is unclear whether this is actually a } \\
\text { randomised controlled trial. The demography and parity of the sample was not reported therefore findings } \\
\text { could not be interpreted }\end{array}$ \\
\hline
\end{tabular}




\section{DATA AND ANALYSES}

This review has no analyses.

\section{A P P E N D I CES}

\section{Appendix I. Search methods for previous version of the review}

We searched MEDLINE (1974 to April 2005), EMBASE (1974 to April 2005), CINAHL (1982 to April 2005) and PsycINFO (1887 to April 2005) using the subject heading cesarean section and the free-text terms (cesarean or caesarean or caesarian or cesarian) and (birth or delivery) combined with the free-text terms (choice or inclination or behaviour or decision or prefer or request or demand or want or wish or favour or desire or fancy or rather or thoughts or feelings or opinion or view or like or attitude).

We also performed a manual search of the references of all retrieved articles. We sought unpublished papers and abstracts submitted to international conferences and contacted expert informants.

\section{WHAT'S NEW}

Last assessed as up-to-date: 27 April 2009.

\begin{tabular}{|c|c|c|}
\hline Date & Event & Description \\
\hline 28 April 2009 & New search has been performed & Search updated. No new trials identified. \\
\hline
\end{tabular}

\section{H I S T O R Y}

Protocol first published: Issue 1, 2004

Review first published: Issue 3, 2006

\begin{tabular}{lll}
\hline Date & Event & Description \\
\hline 10 November 2008 & Amended & Contact details updated. \\
\hline 13 August 2008 & Amended & Contact details updated \\
\hline
\end{tabular}




\section{CONTRIBUTIONS OF AUTHORS}

T Lavender, C Kingdon and G Gyte reviewed the papers. T Lavender and C Kingdon wrote the first draft of the review. G Gyte, J Neilson and G Hofmeyr commented on review drafts. The final version of the review is representative of the contribution of all authors.

\section{DECLARATIONS OF INTEREST}

None known.

\section{SOURCES OF SUPPORT}

\section{Internal sources}

- University of the Witwatersrand, South Africa.

- University of Central Lancashire, UK.

- The University of Liverpool, UK.

- Liverpool Women's NHS Foundation Trust, UK.

\section{External sources}

- HRP - UNDP/UNFPA/WHO/World Bank Special Programme of Research, Development and Research Training in Human Reproduction, Geneva, Switzerland.

\section{N DEX TERMS}

\section{Medical Subject Headings (MeSH)}

${ }^{*}$ Cesarean Section [adverse effects; psychology]; *Term Birth

\section{MeSH check words}

Female; Humans; Pregnancy 